\title{
A new perspective on neutralization and deterrence: Predicting shadow IT usage
}

\author{
Mario Silic ${ }^{\mathrm{a}, \mathrm{c}}$, Jordan B. Barlow ${ }^{\mathrm{b}, *}$, Andrea Back ${ }^{\mathrm{a}}$ \\ a University of St. Gallen, IWI-HSG, Büro 51-4008, Unterer Graben 21, 9000 St. Gallen, Switzerland \\ ${ }^{\mathrm{b}}$ Department of Information Systems \& Decision Sciences, California State University, Fullerton, 800 N. State College Blvd., Fullerton, CA 92831, USA \\ ${ }^{\mathrm{c}}$ Zagreb School of Economics and Management, Jordanovac 110, 10000 Zagreb, Croatia
}

\section{A R T I C L E IN F O}

\section{Article history:}

Received 26 April 2016

Received in revised form 24 January 2017

Accepted 5 February 2017

Available online xxx

\section{Keywords:}

Neutralization

Deterrence

Employee IT compliance

IT security policy

Shadow IT

\begin{abstract}
A B S T R A C T
This study examines the role of neutralization and deterrence in discouraging employees from using Shadow IT: tools, services and systems used in an organization but not authorized by the IT department. Our study provides a unique contribution to the IT security literature by studying effects of neutralization on both intentions (self-reported) and actual behavior, as well as examining the role of shame as a mediator. We surveyed employees from four organizations and found that the "metaphor of the ledger" neutralization technique predicts Shadow IT intention and actual Shadow IT usage. We also find that neutralization and deterrence effects influence shame.
\end{abstract}

(c) 2017 Elsevier B.V. All rights reserved.

\section{Introduction}

Intentional or accidental violations of information security policies are one of the top concerns for information security managers as they strive to protect organizational assets from their own employees [1]. These employees, commonly referred to as organizational insiders, are individuals that have access to organizational assets as a routine and standard part of their roles and responsibilities. This provides them access privileges and intimate knowledge of internal organizational processes that may lead to vulnerabilities for the organization [2]. A survey of more than 500 US IT executives done by PwC [3] reported that $32 \%$ of participants say insider violations are more costly or damaging than incidents perpetrated by outsiders. More worrying, the same report says that only $49 \%$ of all respondents have a plan for responding to insider threats. The Global State of Information Security survey of $9700 \mathrm{CxOs}$ [4] found that the top security threats were the result of current and former employees. Thus, understanding insider threats is considered one of the most difficult challenges that security researchers and professionals face today $[5,6]$.

Employee non-compliance stems from various sources. One is that some employees, instead of using the formal and standard

\footnotetext{
* Corresponding author.

E-mail address: jobarlow@fullerton.edu (J.B. Barlow).
}

systems already present in their organizations, often will violate information security policy by accessing external systems which will enable them to be more efficient and effective [7,8]. This insider threat is termed Shadow IT usage. Shadow IT represents all hardware, software, or any other technological solution used by employees inside of the organizational ecosystem that did not receive any formal IT department approval and is not prescribed by the formal policy [9]. One such example is the use of consumer cloud systems (e.g., Dropbox), which are used by employees without any formal IT department approval. An IBM survey showed that one third of Fortune 1000 employees are regularly saving and sharing company data to external cloud-based platforms, which is bringing important security threats [10]. A survey of cloud usage of 200 IT and security professionals across the globe found that $72 \%$ of organizations do not know what type of Shadow IT apps are used within their organizations [11]. Shadow IT is situated in the fringes of organizations where it fills the existing gap between users and the solutions provided by the IT department [12]. Shadow IT usage can thus be classified as a volitional action, where the employee is deliberately doing an action, but without any malicious intentions [2].

Against this background, research is needed to better understand the reasons why employees do not comply with organizational information security policies regarding the usage of Shadow IT. Deterrence theory, one of the most widely applied theories in information systems, suggests that human behavior can be controlled by the threat of sanctions, which can be an efficient 
technique to deal with employees' negligence of the IT security policies [13]. However, the IS deterrence literature has produced some discrepant findings, suggesting an uneven and often contradictory understanding of the influence of sanctions [14]. Consequently, employees may continue to violate security policies despite being aware of possible sanctions they may incur. One explanation for this behavior is the use of neutralization techniques (i.e., justifying poor behavior) [15,16]. Neutralization theory suggests that citizens that abide by rules and those who do not both believe in the norms and values of the community in general [16]. Hence, an employee that performs a deviant action will justify that behavior, for example with the argument that no damage was really done [16]. The argument advanced in neutralization theory is that an individual is often able to avoid self-censure by cognitively redefining situations in a way that minimizes culpability in their own eyes [17].

While neutralization theory does provide a good theoretical foundation to better understand the scope of insider threats, we still lack empirical research connected to specific forms of computer abuse [2]. Specific neutralization techniques can be suited to specific deviant acts [16]. Shadow IT is a specific organizational violation that would be interesting to study to understand which rationalizations are associated with it. Almost no research has been conducted at the individual level regarding potential predictors and antecedents of Shadow IT usage as a norm violation [18]. Thus, our first research question is as follows:

RQ1: Which rationalizations are associated with the usage of Shadow IT, and by comparison, which forms of deterrence are effective in reducing Shadow IT usage?

One limitation of past studies on neutralization is the use of vignette-based instruments where participants read scenarios and then answered questions in a survey $[19,20]$. This type of study can lead to social desirability bias because it does not assess real-world behavior. Indeed, several studies suggest that in an information security context, the measurement of actual behaviors is more preferable and realistic than the measurement of self-reported intentions [21-23] because intentions do not always lead to behavior [23]. Further, researchers have called for more studies to examine the link between intentions and actual security behavior [24]. No study on neutralization techniques in information security has examined this important relationship. The Shadow IT phenomenon represents a context that enables the assessment of actual behavior in organizations. As such, it offers an interesting setting to further understand employees' compliance with IT security policies while using neutralization techniques. Therefore, our second research question is as follows:

RQ2: Which rationalizations are associated with actual Shadow IT organizational policy violations and which are associated with stated intentions, and how do these differ?

Another issue with past research on neutralization and deterrence is that the interaction between them is unclear. Traditional research on deterrence considers formal sanctions, informal sanctions, and shame as separate constructs that directly affect self-reported intentions to violate security policy, but do not consider the interaction of these constructs [13,15]. However, some research indicates that shame plays a mediating role between sanctions, risk perceptions, and ultimate behavior [25]. Shame may similarly mediate the effects of neutralization techniques on ultimate behavior. Neutralization theory suggests that employees use neutralization techniques to mitigate feelings of shame, which could decrease the deterrent effect [26,27], but this relationship has not previously been studied in research examining the effects of neutralization on information security compliance and violation [15,19][e.g.,15,19]. Therefore, our third research question is as follows:
RQ3: Is shame a mediating factor of neutralization techniques and organizational policy violations, specifically in the context ofShadowIT?

This study, therefore, provides three unique contributions to the organizational information security literature by (1) examining neutralization in the important context of Shadow IT usage; (2) studying the effects of neutralization on both stated intentions and actual behavior; and (3) examining the relationship between deterrence and neutralization in information security, particularly the role of shame as a mediator of other deterrence and neutralization constructs.

\section{Theoretical background}

Insider abuse or employee noncompliance with information systems (IS) security policies is a key concern for organizations that has been widely studied in past research. Numerous studies have dealt with this phenomenon by examining compliance or noncompliance with organizational policies [2]. In past studies, several insider behavior models have been proposed, such as rational choice and beliefs [28], fear [29], accountability [30], selfcontrol and moral beliefs [31], disgruntlement [2], and leadership and organizational culture [32]. This study focuses on two particular theories to predict usage of Shadow IT in the workplace: deterrence and neutralization theories. There are any number of theories that could be appropriately applied to the context of studying Shadow IT. Indeed, the literature often states that rational choice theory is closely related to deterrence theory (Nagin \& Paternoster 1993). We agree with past studies on neutralization which have called for further studies to better understand "the causal effect of neutralization on noncompliance in a variety of circumstances" [15]. While we could gain key insights from rational choice theory, such theory would not direct explain the use of justification in using Shadow IT, which we believe is prevalent in practice.

\subsection{Deterrence theory}

Deterrence theory has been widely used in IS to better understand how to mitigate and combat employees' negligent IS security policy compliance [13-15,33-36]. Deterrence theory explains that individuals will rationally assess what could be the consequences of their decision if they commit a violation. Deterrence theory states that undesirable behavior can be deterred not only by formal sanctions, but also informal sanctions and shame [27,37]. Shame relates to the feeling of guilt one has as a result of others find out about one's wrongdoings [26,38].

Overall, deterrence theory posits that when the risks that are associated to certain behaviors outweigh the benefits behind the violation of the IS security policies, employees will be deterred and, consequently, will not violate the policy. These sanctions behind deterrence may take the form of formal sanctions (e.g., lowering of the salary, negative performance review, etc.) or informal sanctions (e.g., negative feedback received from peers or leaders). Research has confirmed that shame acts as a deterrent and will decrease and impact employees' motivation to commit violations $[15,27]$. Shame, defined as a feeling of guilt as a result of others knowing of one's socially undesirable actions [38], was studied as a separate deterrence construct in past studies [26,27,36].

However, research has not examined the effects of deterrent sanctions and shame on Shadow IT usage. Many organizations may not even have formal sanctions in place for using Shadow IT. Further, the effects of shame on Shadow IT usage may be different than in other circumstances because less stigma surrounds Shadow IT usage, considering that such behavior is pervasive in today's workplace. 


\subsection{Neutralization theory}

Even in the presence of sanctions, employees still violate IT security policies. The intention behind such actions can be either malicious or benign [39,40]. Employees often rely on moral reasoning [31] or neutralization to justify their misbehaviors despite existing organizational sanctions [15].

Neutralization is the act of rationalizing or justifying an immoral or illegal act. Neutralization theory suggests that those who commit illegal or illegitimate actions may 'neutralize' certain values which, in other situations, would prohibit them from committing these same actions [16]. In the organizational context, employees sometimes use one or more neutralization techniques as a mechanism to persuade himself or herself that policy violation does not represent a problem. It can also be seen as a defense mechanism through which people downplay the repercussions of their behavior [41]. This leads to reduction or elimination of the shame that they would normally feel when they knowingly violate IT security policies [2].

In original work on neutralization theory, Sykes and Matza [16] explained five types of neutralization: (1) denial of responsibility (person defines him/herself as lacking responsibility); (2) denial of injury (minimizes the action and the harm it can cause); (3) denial of the victim (offender believes that the victim deserved whatever action the offender committed); (4) condemnation of the condemners (one's behavior is neutralized by blaming the targets of the action); and (5) appeal to higher loyalties (the benefit of violation is superior to the cost of violating a law or policy) [16]. Several other neutralization techniques have been theorized and discussed in subsequent research on neutralization, including "metaphor of the ledger" (the good done by the individual outweighs any bad action they perform) [42] and "defense of necessity" (the behavior was necessary to perform some necessary other action) [43]. Multiple other neutralization techniques, beyond the scope of this study, have also been studied in subsequent research [2].

Because there are many neutralization techniques in the literature, it is common in neutralization studies to omit those neutralization techniques that are not directly relevant to the study $[15,44]$. We chose to focus on the subset of neutralization techniques that were most relevant to the context of deciding whether to violate the organizational policy of using Shadow IT in the workplace. We omit the "denial of the victim" technique from our study because most users have difficulty pinpointing the victim of information security policy violations [15]. In Table 1, we list the neutralization techniques used in this study and present examples of what each neutralization technique or claim might look like from an employee perspective.

Neutralization theory has been used in several different contexts to understand how neutralization techniques influence user's behavior. Ingram and Hinduja [45] found neutralization plays an important role in explaining why individuals pirate software. Use of organizational Internet resources for private use was studied by Lim [46] to understand and compare personal levels of deviance with non-deviant levels of behavior. Lim [46] found that "metaphor of the ledger" [42] was explanatory of violations in this context. For Harrington [47], the technique called "denial of responsibility" had significant correlations with the intention to commit computer violations and the judgement that the non-compliant behavior is acceptable.

More recently, multiple studies in the information systems literature have examined the role of neutralization in predicting user intentions to violate policies [15] and how to best address the tendency to neutralize [19]. Siponen and Vance [15] examined multiple neutralization techniques together in the context of multiple types of policy violations. Barlow et al. [19] examined neutralization techniques in the context of password sharing. Neither study examined actual security behavior (instead measuring intentions) nor the relationship of neutralization techniques with shame (instead only measuring direct relationships with intentions). All of these studies have been useful in examining neutralization in various contexts, but none has yet examined how neutralization explains the use of Shadow IT in organizations.

\subsection{Neutralization in shadow IT usage}

According to Willison and Warkentin [2], neutralization techniques are most influential in the organizational context where they are mostly invoked. Neutralization techniques can be applied differently depending on the context and the specific type of policy being violated [19]. For example, insiders may use a different technique to rationalize sharing passwords as they do when rationalizing stealing information. Hence, we need more studies that examine how neutralization plays a role in deviant behavior in specific contexts. Shadow IT is one important and common context that may be different from other violations previously studied in the IS security literature. Usage of Shadow IT may be especially influenced by neutralization techniques, considering the increase in its usage and its common occurrence in organizations today.

There are several different terms to describe the Shadow IT phenomenon (e.g., rogue IT, shadow systems, workaround systems, or feral systems). We use the term Shadow IT in this study because it seems to be the most widely accepted in the literature. Shadow IT is often seen as a security threat [48] where a non-malicious employee installs and uses non-approved software. Shadow IT has an important dual-use context [9,49], meaning that it can have positive effects on the organizational ecosystem, but can also bring about negative consequences. On the negative side, Shadow IT is said to undermine the official system [50] or even damage organizational data and processes [51]. On the positive side, Shadow IT systems can be efficient and/ or effective when used in place of the formal and standard systems already present $[7,8]$. Due to the potential advantages of using Shadow IT, employees could potentially neutralize their use of such IT, making it a unique and important context in which to study neutralization techniques. Similar to past studies, and relying on the information security threats taxonomy [52], we categorize Shadow IT as an insider threat caused by an employee or human factor. This insider-driven threat is considered non-

Table 1

Neutralization techniques with representative lay statements adapted from [41] to fit the Shadow IT context.

\begin{tabular}{|c|c|}
\hline Type of Claim & Lay Statement Representative of Claim \\
\hline Denial of responsibility & It is not my fault that my organization provides tools that are not as efficient as my cloud storage tool. \\
\hline Denial of injury & No one got hurt by my use of a zip tool I download on my own. \\
\hline Defense of necessity & When times are better, I will change my behavior. Right now, it is necessary to use this external tool to complete my work. \\
\hline Condemn the condemner & Everyone else, including you, is using software beyond the programs formally approved by the organization. \\
\hline Appeal to higher loyalty & I used an external tool to protect, or take care of, someone. \\
\hline Metaphor of the ledger & My use of external cloud storage tools is more than made up for by the efficiency it brings to the organization. \\
\hline
\end{tabular}


malicious because employees do not have intentions to cause damage.

While past literature increasingly gives more importance to the Shadow IT phenomenon [53,54], current knowledge is still rather limited and scarce [18]. Past focus was mostly studying causes of Shadow IT [7], consequences [7,9,12] and governance challenges [48] in the organizational context. However, no explicit theoretical justification nor empirical investigation on the antecedents and consequences of employees' Shadow IT usage was performed [18]. Consequently, there exists a gap in understanding whether neutralization techniques could be a good explanation of such behavior in the specific Shadow IT context.

\subsection{Relationship between deterrence and neutralization effects}

Another area relevant to the organizational context is the relationship between the neutralization techniques and deterrence [2]. Indeed, employees use neutralization techniques to minimize or mitigate the feelings of shame that are connected to the deviant act itself [15]. However, despite the theory that neutralization works by reducing potential shame, no studies have examined this relationship empirically in determining its effects on information security behavior. Rather, previous studies of neutralization (e.g., Siponen and Vance [15]; Barlow et al. [19]) have considered the variables as completely separate from deterrence and direct predictors of intentions or behavior.

More recent research also indicates that shame plays a mediating role between sanctions, risk perceptions, and ultimate behavior [25]. In other words, rather than shame and sanctions having a similar direct effect on behavior, these constructs can, in some cases, mediate each other through more indirect effects. The same could be theorized of the effects of neutralization techniques on behavior and intentions, though this relationship has not been directly tested, particularly in the information security literature.

\section{Hypothesis development}

We predict, based on deterrence theory, neutralization theory, and previous information security literature and theory, that compliance with organizational Shadow IT policies can be predicted by various neutralization techniques, in addition to the deterrent effects of formal sanctions, informal sanctions, and shame. To better compare our study and results to similar prior research in information security compliance, we examine the same six neutralization techniques that were tested in [15]. Unique to our study, we explain each theoretical mechanism in terms of the Shadow IT context. We also theoretically explain how, consistent with both deterrence and neutralization theories, shame can partially mediate each of these relationships. We depict our research model below in Fig. 1 .

\subsection{Deterrence techniques}

\subsubsection{Shame}

Because shame is a feeling of guilt as a result of others' awareness of one's own violation of IS security policies, it can be seen as a deterrent as it can have similar effects as other sanctions. Its deterrent effect is similar to formal or informal sanctions and its effect has been shown to be significant in past studies $[15,27,36,37,55]$. Because Shadow IT usage is common and may have less stigma associated with it, shame may not be as powerful as in other contexts. However, according to deterrence theory, if an employee deliberately uses Shadow IT tools, he or she may feel guilt if his or her actions are publically advertised, reprimanded, or made aware among peers. The potential shame anticipated by the employee will decrease the individual's intentions to use such Shadow IT. Hence, we hypothesize that:

"H1. Shame is negatively associated with intentions to use Shadow IT in violation of IT security policies."

\subsubsection{Formal sanctions}

Formal sanctions represent explicit penalties resulting from certain forms of misbehavior [15]. D'Arcy, Hovav and Galletta [13] found that IS misuse intention will be reduced if user awareness of security countermeasures is clearly associated with the severity of organizational sanctions - if severity of sanctions is high, the IS misuse intention will be lower. The same argument could be made for certainty and celerity (i.e., immediacy) of sanctions. Although

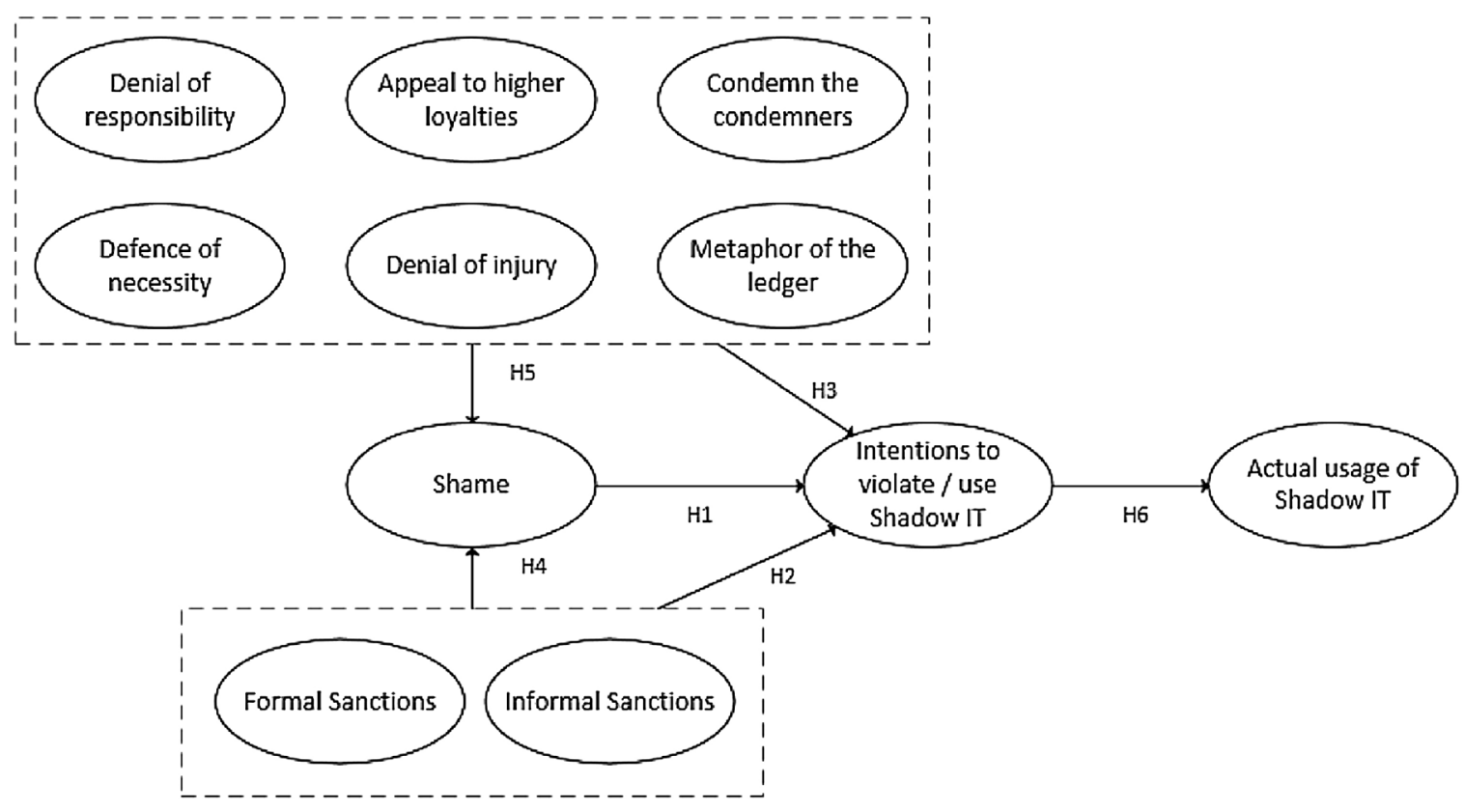

Fig. 1. Research model. 
Shadow IT usage is pervasive and some organizations may not currently enforce sanctions for such behavior, the act of an organization to punish employees for such behavior would likely be a deterrent to future Shadow IT usage. That is, when employees anticipate that the certainty, severity, and celerity of sanctions in place for using Shadow IT will be high, they will avoid violating the policy in an effort to avoid the associated sanctions. Consistent with deterrence theory, we hypothesize that:

"H2a. Formal sanctions are negatively associated with intentions to use Shadow IT in violation of IT security policies."

\subsubsection{Informal sanctions}

Informal sanctions refer to disapproval from one's peers as a result of violating a rule or social norm. Deterrence theory posits that individuals perceive potential informal sanctions, as with formal sanctions, to have some level of severity, certainty, and celerity. When individuals perceive the potential severity, certainty, and/or celerity of informal sanctions as high, the fear of disapproval from peers for violating the policy will deter noncompliant behavior. In the context of Shadow IT, if individuals perceive that co-workers or others will disapprove of the individual using unauthorized software or hardware, they are then less likely to install and use such software. The pervasive use of Shadow IT in many organizations may lead to fewer informal sanctions occurring. However, consistent with deterrence theory, we hypothesize that when informal sanctions do occur:

"H2a. Informal sanctions are negatively associated with intentions to use Shadow IT in violation of IT security policies."

\subsection{Neutralization techniques}

\subsubsection{Defense of necessity}

The "defense of necessity" permits an individual to rationalize that no other choice exists $[15,43]$. When individuals use this technique, they assume that, even if violating a policy is morally wrong, such violation is necessary [41]. In the organizational context, when employees rationalize that no other choice is possible, they also believe that they are not guilty for eventually violating the policy. Specifically, if an employee considers that he or she must complete certain work in a daily routine, he or she may feel that a certain software, not approved by the organization, will be necessary to complete the work. For instance, if an employee needs to automate daily tasks, he or she can use Excel plug-ins found online. By doing so, the employee will download and install a software plug-in that will speed up the employee's daily tasks but which can also introduce security risks because the plug-in was not previously screened by the IT department. Still, the employee believes that using the plug-in is the only way to proceed because doing differently could jeopardize his or her productivity. Hence, this neutralization is particularly salient to Shadow IT usage, and we hypothesize that:

"H3a. Use of the "defense of necessity" neutralization is positively associated with intentions to use Shadow IT in violation of IT security policies."

\subsubsection{Appeal to higher loyalties}

"I did it to protect, or take care of, someone," is a typical statement that describes this neutralization. Usually, when individuals break the law or go against the community expectations to meet the needs of their group, friend, or family, they are appealing to higher loyalties [41]. A popular example of this behavior is that an individual gets into trouble for helping a friend and claims, "I will not betray my friend. I will not be an informant". In this case, any harm is justified if individuals remain within their group or friends' circle. The consequence is that the individual does not reject societal norms; rather, he or she places the importance of such norms in second place - right after the group or friends' circle. In the context of Shadow IT, employees could convince themselves that using certain unapproved software will help the organization to be more productive or profitable-perhaps some greater benefit to the organization could be achieved by the employee using this software to improve his or her work. That is, the employee says that his or her loyalty to their work and the organization is superior to any policy that may advise against the use of such technology. Hence, we hypothesize that:

"H3b. Use of the "Appeal to higher loyalties" neutralization is positively associated with intentions to use Shadow IT in violation of IT security policies."

\subsubsection{Condemn the condemners}

In this neutralization technique, the individual will counterattack by accusing the ones who accuse him or her. When people condemn the condemners, the blame for the loss lies on the community instead of the individual. There are two common sentiments that describe this situation well: "Everybody else is doing it. Why focus on me?" and "You do the same thing, so don't point fingers at me". Employees that embrace this neutralization technique will deflect attention away from their acts toward the person who is accusing them of the noncompliant act. For example, in the Shadow IT context, employees could argue that if they use Dropbox to store organizational data, that everyone, including those enforcing IT security policies, is doing the same. Typically, employees will claim that everybody is storing organizational files using cloud services and that nothing is wrong in doing so. Hence, we hypothesize that:

"H3c. Use of the "Condemn the condemners" neutralization is positively associated with intentions to use Shadow IT in violation of IT security policies."

\subsubsection{Metaphor of the ledger}

When using this technique, an individual will claim, "My lack of judgement is more than made up for by rightness in other parts of my life." Employees that engage in such delinquent behavior will strongly argue that all the good things they did will make up for the illegal behavior. For instance, if an employee uses software that is unauthorized, he or she might say, "There is nothing wrong in this if I consider what the company owes me. If I do any wrong, it is only to compensate for all the long hours I spent working for the company and all the extra-long unpaid shifts." This justification is based on the idea that individuals tend to accumulate some credits (brownie points) that they will likely "cash-in" at a certain point as an excuse to break the rules. Hence, we hypothesize that:

"H3d. Use of the "Metaphor of the ledger" neutralization is positively associated with intentions to use Shadow IT in violation of IT security policies."

\subsubsection{Denial of injury}

When this neutralization technique is used, people have high confidence and believe that no one will get hurt by the actions they commit. In this case, people do not deny their actions; they simply think that no harm will be done. Employees using Shadow IT will usually think that no harm or no IS security policy violation occurs if they use Shadow systems. For example, if an employee creates an Excel macro, he or she will argue that a simple macro cannot do any damage to organizational assets if the macro remains on a local PC; thus, it does not represent any danger. Therefore, employees will be convinced that there is no reason to feel shame. Hence, we hypothesize that:

"Н3e. Use of the "Denial of injury" neutralization is positively associated with intentions to use Shadow IT in violation of IT security policies." 


\subsubsection{Denial of responsibility}

Individuals that use this technique usually reject their responsibility and believe that certain circumstances predisposed them to act as they did. In the organizational context, "peer pressure" could be one of the triggers or reasons to use this technique; in other words, employees may rationalize their behavior by saying that peer pressure was too high and the consequence was that they had to violate the security policy. For example, if a boss asks an employee to do a certain task which can be completed only if the employee uses some unapproved software tools, the employee may explain that he or she is a victim of circumstance where he or she was pushed beyond their control (accomplish the task with unapproved software tools). For example, a manager might ask an employee to assess new contract leads, which he or she can do in a short amount of time only by using some open source business intelligence tools (e.g. JasperReport). Hence, we hypothesize that:

"H3f. Use of the "Denial of responsibility" neutralization is positively associated with intentions to use Shadow IT in violation of IT security policies."

\subsection{Shame as a mediator of deterrence/neutralization and intentions}

Consistent with deterrence theory, we hypothesize that if employees receive formal sanctions for using Shadow IT, these sanctions will cause the employee to feel shame for their actions. Recent research has indicated that shame, though a deterrent factor itself, mediates the relationship between other deterrence factors and ultimate behavior [25]. However, such mediating relationships between shame and other deterrence constructs have not been tested in the context of organizational IT security policies, nor in an international, cross-cultural context. In other words, formal sanctions not only have a direct effect on intentions (because individuals do not want to receive the sanctions), but this relationship is also partially explained by the increased shame that individuals feel when they perceive that they will receive sanctions, which in turn will lower intentions. Therefore:

"H4a. Formal sanctions are positively associated with shame."

Therefore, shame partially mediates the relationship between formal sanctions and intentions to use Shadow IT in violation of IT security policies.

Further, informal sanctions will lead to shame because the potential negative feedback from coworkers and peers for violating a policy will cause the individual to feel shame if they violate the organization's security policy (in this case, Shadow IT). Even though deterrence theory suggests shame mediates the effects of informal sanctions on behavior, we are not aware of any studies that directly test this relationship empirically. Following deterrence theory, we posit:

"H4b. Informal sanctions are positively associated with shame."

Therefore, shame partially mediates the relationship between informal sanctions and intentions to use Shadow IT in violation of IT security policies.

Individuals reduce the guilt that they would perceive in committing a violation of the policy by neutralizing their behavior [15]. In this case, individuals reduce the guilt of using unauthorized software by convincing themselves of various justifications to use the software; thus, there should be no need to feel guilt. If they are later known by others to have violated the policy, their feelings of guilt will not translate into shame. In other words, shame is a feeling of guilt when others know of the behavior. If the individual has no guilt in committing the behavior, then they will feel no shame if others find out about the behavior. While they may feel shame in violating policies in general, the perception that using Shadow IT is good, for various justifications outlined above, will reduce the potential shame they might perceive when deciding to commit this violation. Therefore, we hypothesize:

"H5. Use of neutralization techniques is negatively associated with shame."

Therefore, shame partially mediates the relationship between neutralization techniques and intentions to use Shadow IT in violation of IT security policies.

\subsection{Intentions and behavior}

Although it is necessary to distinguish behavioral intentions (self-reported intention) from actual behavior (non-self reported) in both research and practice [23], intentions do have a strong effect on the ultimate behavior of individuals. The strong relationship between intentions and behavior is theorized in the Theory of Reasoned Action [56], the Theory of Planned Behavior [57], and many subsequent studies that empirically test these theories, including in information systems and information security literature [e.g.,58]. These theories state that behavior is largely a function of a person's deliberate intentions to act in a certain way, although somewhat moderated by perceived behavioral control. In the IS literature predicting technology usage, behavioral intentions are largely found to predict actual IT usage $[59,60]$. In the context of this study, if individuals intend to use Shadow IT, there is reason to believe that they will actually do so, assuming they perceive they have the capability to do so. Therefore, based on these theories, we hypothesize:

"H6. Intentions to use Shadow IT are positively associated with actual Shadow IT installation."

\section{Research design}

\subsection{Participants}

To test our research hypotheses, we conducted a field survey. Because compliance behavior is linked with the security climate of individual organizations [61], we chose to engage multiple organizations in our study. Specifically, we conducted the survey with four industry organizations: a major financial company (insurance), USA based, that has high international presence; a French company doing toll road management (present in six countries); a bank institution from Croatia; and an IT company having presence in three European countries. The reason for selecting these four organizations is because the understanding of the Shadow IT issue was consistent across all four organizations in such a way that they all consider Shadow IT to be an IT system and solution that is outside of the IT department ownership or control that did not receive any formal approval from the IT department. To this respect, Shadow IT violations (e.g., using Dropbox) were similar in all four organizations. Thus, as explained in procedures section, we used the same types of Shadow IT violations in the survey. Finally, none of the organizations had a standalone Shadow IT policy; rather, it was an integral part of a larger IT security policy. Further, in each of the organizations, management takes visible steps to try to prevent Shadow IT usage. For example, when users try to access dropbox.com in one of the organizations, users see a screen stating, "Attention: CompanyX does not allow access to websites categorized as 'Personal Network Storage'. Please use Box instead to help keep CompanyX's information secure." Thus, users in these organizations should be aware that the organizations discourage use Shadow IT use.

Targeted participants from all four organizations were managers (all levels from IT to product management), marketing people, and administrative staff and finance employees. The reason for restraining the sample was because organizations did not want us to launch the survey targeting all their employees, but also since 
these functions mostly deal with processes, procedures, and customers where IT use is usually higher when compared to, for instance, employees involved in fully automated tasks. All four organizations have strict procedures and policies in place when it comes to IS security policies. These policies clearly define roles and responsibilities of each employee, formal sanctions applied in case of policy violations, and ethical guidelines on which management should train each employee.

We followed the recommendations of [62] to analyze if our sample size would provide good power and reliability of our model results. We calculated statistical power by taking into account our sample size (440), the observed probability level (0.05), the number of predictors (8) and the observed $R^{2}(0.291)$. Results indicated that our sample size provides sufficient power to detect significant effects.

\subsection{Measures}

We measured all items (except actual Shadow IT usage) on an 11-point Likert scale from 0 to 10 that we adapted from previously validated instruments $[15,26]$. A list of all items is depicted in Table A1 (Appendix A). We note that behavioral intention corresponds to self-reported intentions to be non-compliant with the Shadow IT aspects of IT security policies. Actual behavior is non self-reported misuse of IT security policy where an employee is using Shadow IT without any prior formal approval from the IT department. The measure of actual behavior is explained in the Procedures section and corresponds to a binary outcome ( 0 or 1 ) showing compliance or non-compliance. Consistent with past studies $[15,63,64]$, we measured deterrence constructs by multiplying each certainty measure by its associated severity measure to form a single construct that reflects both certainty and severity of deterrence.

Ten information security managers reviewed all items. After a consensus was reached (four rounds), the survey was pretested with pre-selected employees in two participating organizations (one USA and one French company). In total, we had 80 responses. The pre-test enabled us to conclude that our model yielded acceptable results (we tested reliability of measurement items for each construct using Cronbach's $\alpha$; convergent and discriminant validity using principal components analysis; results of these tests are documented in Appendix B). In addition, the survey was first translated into French and Croatian languages (by French and Croatian doctoral students) to avoid any misinterpretation and then translated back to English (by French and Croatian master students) to avoid any distortion during translation. Three minor adjustments were made. Finally, one last round of translation was done by bi-lingual translators, which resulted in an accurate translation. In the company that had international presence (mainly in UK, France, Germany, Spain, and Ireland), we asked the company to distribute the survey in English or French only to employees for who these languages were their first language. This was made possible through an automated company's internal HR system.

Contrary to the hypothetical scenario method where a vignettebased approach is used, we sought to measure behavior of the participant directly. However, due to social desirability bias, asking participants to indicate if they are Shadow IT users could potentially produce fake results without further checking and verifying their claims. Therefore, to have the most accurate possible assessment of Shadow IT usage, we asked IT departments of participating organizations to provide us with the list of all shadow software installed and used, based on the IP and MAC addresses which were matched to the anonymous survey responses. Thus, our dependent variable was a binary indicator of whether the participants had actually installed Shadow IT software.

\subsection{Procedures}

The survey was distributed by each company's IT department, except for the French company, where the survey was sent out by the CEO (the company does not have an IT department). In order to bring more specificity, and avoid any possible misunderstanding of what Shadow IT is, we provided three clear examples to participants of the most common Shadow IT policy violations as suggested by Silic and Back [9], which included (1) self-made Excel macros; (2) PDF tools; and (3) cloud services such as Dropbox. By doing so, we complied with the guidelines suggested for improving contextual relevance in IS security research [65]. In other words, the survey question asked generally about Shadow IT, but directly below that question were three examples of potential Shadow IT tools.

Rather than relying on vignette-based scenarios, we aimed to minimize bias by assessing real-life situations. This was possible because each participating organization has technology (e.g., IBM BigFix) that enables them to track what type of software is installed on end-user devices based on IP and MAC addresses. A report of this data was generated after surveys were completed. The list provided was then matched against the unique IP and MAC addresses we received through the online survey (the survey was anonymous for all participants; however, each survey participant was tracked by their IP and MAC addresses). We excluded nine participants for which we could not find any match. Further, if the participant Shadow IT use response matched the list of unapproved software identified by the organizational tracking software, we considered the participant answer to be true. For example, if the survey participant answered 'yes' to the question 'Did you ever use any shadow IT software?', we checked the corresponding unapproved list of software related to the participant's IP address. By following this procedure, we were able to measure the employee's actual behavior, which was represented as a binary variable: 0:compliant and 1:non-compliant.

Table 2

Descriptive Statistics.

\begin{tabular}{|c|c|c|c|c|c|c|c|c|}
\hline Sample & Sample Size & Response (Rate) & Average Age & $\begin{array}{l}\text { Min } \\
\text { Age }\end{array}$ & $\begin{array}{l}\text { Max } \\
\text { Age }\end{array}$ & $\begin{array}{l}\text { Std. } \\
\text { deviation } \\
\text { Age }\end{array}$ & $\begin{array}{l}\text { Mean } \\
\text { Experience }^{a}\end{array}$ & Male/Female\% \\
\hline Financial company & 900 & 267 (30\%) & 39 & 20 & 55 & 10.37 & 3.06 & $58 \% / 42 \%$ \\
\hline Toll road company & 80 & $41(51 \%)$ & 41 & 21 & 52 & 9.35 & 3.29 & $62 \% / 38 \%$ \\
\hline Bank & 350 & $70(20 \%)$ & 37 & 20 & 55 & 10.65 & 2.98 & $44 \% / 56 \%$ \\
\hline IT company & 115 & $62(54 \%)$ & 40 & 22 & 54 & 9.52 & 2.96 & $75 \% / 25 \%$ \\
\hline Total & 1445 & $440(30 \%)$ & 41 & 20 & 55 & & & $61 \% / 39 \%$ \\
\hline
\end{tabular}

a experience ranged from 1 ( $<1$ year) to 5 ( $>10$ years). 


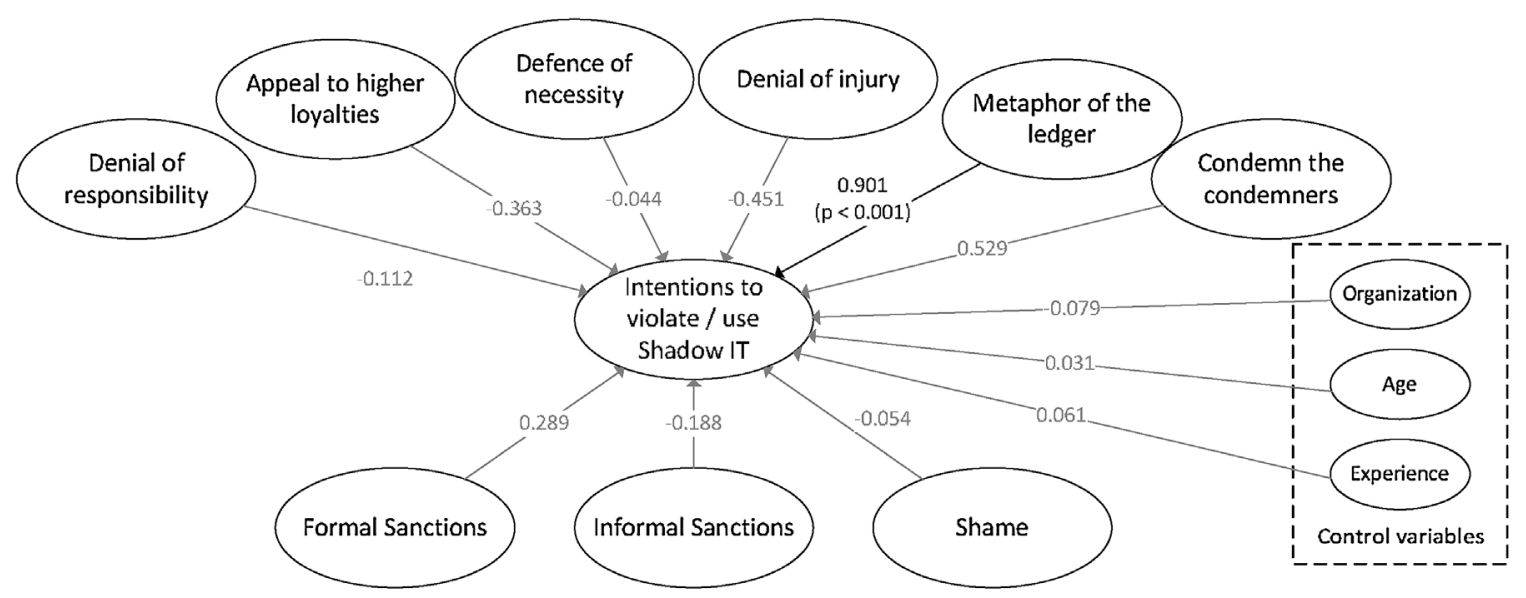

Fig. 2. Direct effects of neutralization and deterrence on Shadow IT intentions*.

Finally, with this approach we were able to get a reliable list of participants that claimed (or not) to have used Shadow IT and consequently, were breaking the IS security policies. Overall, the number of dishonest (claiming in the survey that they do not break any policy but in reality they do) employee answers varied by organization from $4.5 \%$ to $12.8 \%{ }^{1}$ Part of these dishonest answers could be explained by the fact that employees might not be aware that what they are doing is against the IS security policies.

We were also informed that the following actions were taken in all four organizations: (1) users were informed about the noncompliant actions through an email; and (2) illegal software was removed by the IT department when found. In many cases (depending on the type of software and the organization), users were also reported to their managers.

\section{Analysis and results}

\subsection{Descriptive statistics and validity checks}

In total, we had 440 responses from the sample frame of 1445. Table 2 provides detailed descriptive statistics. We removed seven responses for implausible response times (less than $2 \mathrm{~min}$ ) needed to complete the survey (average $15 \mathrm{~min}$ ). Nine responses were removed where we could not match participant survey responses with actual software installation lists.

In order to assure that our model has acceptable convergent and discriminant validity and reliability we performed tests detailed in Appendix B. Our model showed and exceeded all accepted levels and thresholds as required in the IS field. Further, we applied two different procedures (Appendix C) to check the possible threat of common method bias. To make sure that we could combine samples from four different organizations, we analyzed descriptive statistics and concluded that no significant differences among the subsamples should prohibit us from examining the combined dataset.

We used MPlus to test a structural equation model. MPlus allows for a binary dependent variable, and provides logistic regression coefficients for those relationships between continuous variables (most variables in our study) and the binary dependent variable (whether they actually used Shadow IT). In addition, we included age, gender, work experience and industry type to understand their effects on the dependent variables.

\footnotetext{
${ }^{1}$ Croatian bank: 12.8\%; French toll road company: 9.8\%; European IT company: $4.8 \%$; US-based international company: $4.5 \%$.
}

\subsection{Direct effects of neutralization and deterrence on intentions and behavior}

Before testing the full theoretical model, we analyzed two simpler models to compare the effect of neutralization and deterrence on behavioral intention (self- reported) vs. actual Shadow IT usage (non-self-reported). Fig. 2 shows a model similar to previous research on neutralization and deterrence; it shows only direct effects of these constructs on intentions to violate policy. In contrast, Fig. 3 shows the direct effects of neutralization and deterrence on both actual usage of Shadow IT in these organizations.

As shown in Fig. 2, one neutralization technique, namely "metaphor of the ledger," and shame were significant predictors of intentions. However, Fig. 3 shows that shame was not a direct significant predictor of actual Shadow IT usage in violation of policy.

These results are fairly consistent with prior research showing that (1) different neutralization techniques have different effects on violation intentions [19] (as well as on behavior), and (2) neutralization is more powerful than sanctions in predicting intentions to violate information security policies, with none of the deterrence constructs being statistically significant [15]. The effects of neutralization techniques were similar on both intentions and actual usage.

\subsection{Analysis of full model}

Fig. 4 and Table 3 summarize the analysis of the full model.

As shown in Fig. 4 and Table 3, shame surprisingly did not have a statistically significant effect on intentions to violate the Shadow IT security policy, failing to support $\mathrm{H} 1$. This is in contrast to the direct model illustrated in Fig. 2. Shame, therefore, seems to have a small role in reducing intentions to use Shadow IT, but the statistical effect is lost when tested in a larger, more complex model.

Formal and informal sanctions did not have direct negative effects on intentions to violate the Shadow IT security policy, failing to support $\mathrm{H} 2$. One neutralization technique, namely "metaphor of the ledger," was a significant direct predictor of intentions to violate the Shadow IT policy $(\beta=0.695 ; \mathrm{p}<0.001)$, providing support for $\mathrm{H} 3 \mathrm{~d}$. The remaining neutralization techniques were not direct significant negative predictors of intentions, failing to support $\mathrm{H} 3 \mathrm{a}, \mathrm{H} 3 \mathrm{~b}, \mathrm{H} 3 \mathrm{c}, \mathrm{H} 3 \mathrm{e}$, and $\mathrm{H3f}$.

Further, because shame did not have a statistically significant effect, the "shame as mediator" hypotheses (H4, H5) were not fully 


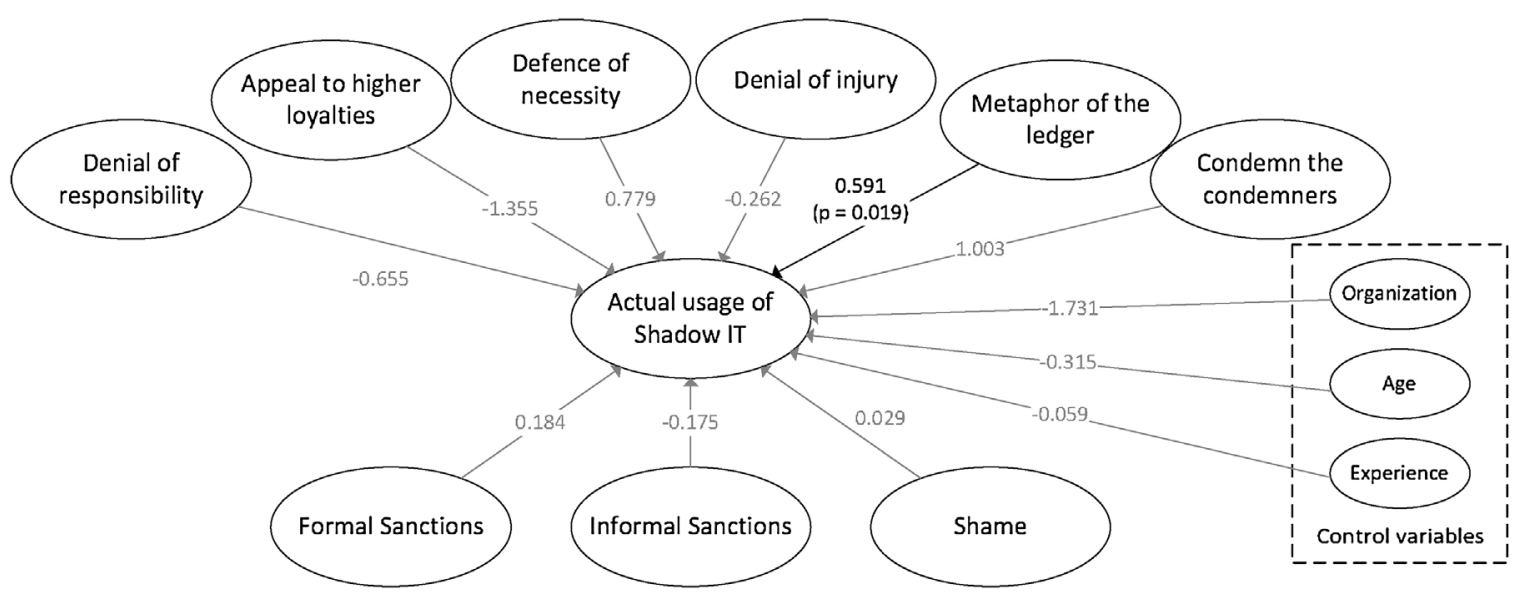

Fig. 3. Direct effects of neutralization and deterrence on actual usage*.

supported. However, neutralization and deterrence do have some effects on perceived shame, regardless of how it ultimately affects behavior. There was no statistically positive effect between formal sanctions and shame, failing to support H4a. However, informal sanctions had a statistically significant positive relationship with shame, providing partial support for $\mathrm{H} 4 \mathrm{~b}(\beta=0.931 ; \mathrm{p}<0.001)$. Regarding H5, only some of the neutralization techniques were significantly related to shame. In addition to the direct effect on intentions, "metaphor of the ledger" had a negative impact on shame $(\beta=-0.122 ; p=0.013)$. The "defense of necessity" $(\beta=-0.321 ; p=0.013)$ and "denial of injury" $(\beta=-0.245$; $\mathrm{p}=0.069)$ neutralization techniques were also negatively related to shame. The other three neutralization techniques had no significant negative effect on shame.

Intentions to violate the Shadow IT security policy were positively associated with actual violation of the policy ( $\beta=0.468 ; p<0.001$ ), supporting $\mathrm{H} 6$. We give a summary of hypothesis support below in Table 4 .

\section{Discussion}

\subsection{Interpretation of findings}

The results of our study support five main findings. First, some past research implies that all neutralization techniques have similar effects [15]. However, similar to the Barlow, Warkentin, Ormond and Dennis [19] study, which found that some neutralization techniques can be more powerful than others, our results also bring a different view of how neutralization techniques can be used in a specific Shadow IT context. In this specific context, only the "metaphor of the ledger" neutralization technique had a strong, direct positive effect on the violation of organizational Shadow IT usage policies. This finding is quite different from the study of Barlow, Warkentin, Ormond and Dennis [19], which investigated the role of neutralization techniques on password sharing practices and found, for instance, that "defense of necessity" is particularly prominent for the password sharing

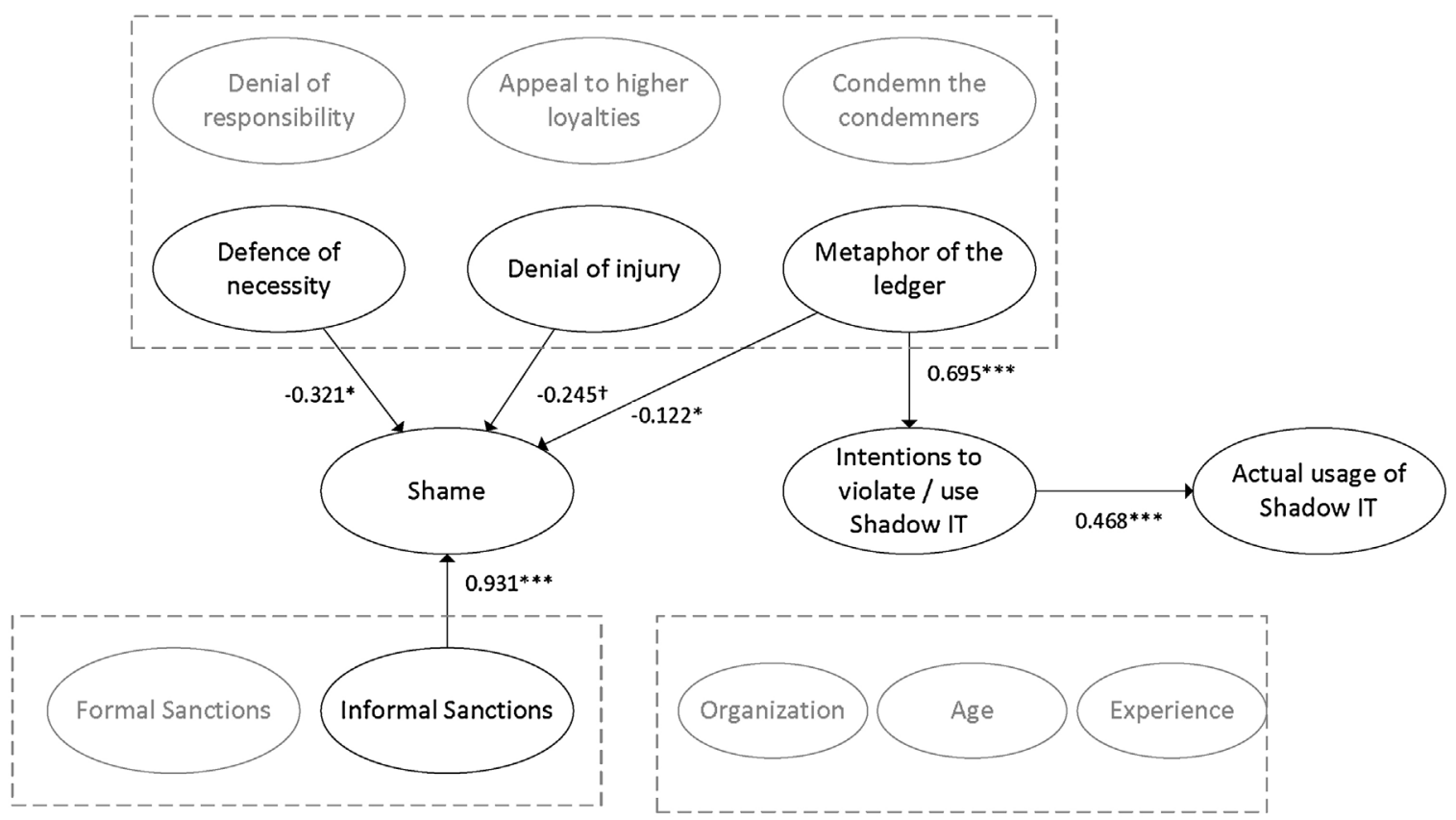

Fig. 4. Results of full model analysis ${ }^{1}$. 
Table 3

Coefficients and p values for full model.

\begin{tabular}{llllll}
\hline \multirow{2}{*}{$\begin{array}{l}\text { Independent Variables } \\
\end{array}$} & \multicolumn{2}{l}{$\begin{array}{l}\text { Relationship with } \\
\text { Shame }\end{array}$} & & \multicolumn{2}{l}{$\begin{array}{l}\text { Relationship with Intentions } \\
\text { to Violate }\end{array}$} \\
\cline { 2 - 3 } \cline { 5 - 5 } \cline { 5 - 5 }$\beta$ & $\beta$ & & $\beta$ & $p$ \\
\hline Formal sanctions & -0.110 & 0.017 & & 0.146 & 0.025 \\
Informal sanctions & 0.931 & $<0.001$ & & -0.172 & 0.188 \\
Defense of necessity & -0.321 & 0.013 & & 0.161 & 0.524 \\
Appeal to higher loyalty & 0.722 & 0.595 & & -0.776 & 0.235 \\
Metaphor of the ledger & -0.122 & 0.013 & & 0.695 & $<0.001$ \\
Denial of injury & -0.245 & 0.069 & & -0.313 & 0.088 \\
Denial of responsibility & 0.279 & $<0.001$ & -1.201 & 0.699 \\
Shame & & & -0.022 & 0.865 \\
Organization & & & -0.117 & 0.086 \\
Age & & & -0.050 & 0.448 \\
Experience & & & 0.107 & 0.315 \\
Actual usage (logistic) & & & 0.468 & $<0.001$ \\
\hline
\end{tabular}

scenario. It seems that in the context of Shadow IT usage, employees intending to violate the policy often consider that the good that they have done will outweigh any negative consequences of using the unauthorized software. Other neutralization techniques are not as powerful in persuading employees to violate this particular policy.

Second, regarding the deterrent constructs, we found that shame, formal sanctions, and informal sanctions did not have any deterring effect on Shadow IT intention. These results regarding deterrent constructs are in line with previous research on deterrence in information systems literature [e.g.,15,64]. Deterrence is more powerful in some contexts than in others [14], and we propose that, consistent with the original assumptions of deterrence theory, in situations where the behavior is more ubiquitous, with less stigma attached, sanctions such as sanctions and shames will be less powerful. This also underscores the calls for research to more fully investigate the varying effects of both neutralization and deterrence for different types of insecure behaviors.

Third, we found that shame is influenced by informal sanctions and some neutralization techniques. While such a relationship has been implied in the theoretical explanations of neutralization and deterrence, this had not been previously tested. Specifically, the metaphor of the ledger, defense of necessity, and denial of injury techniques reduce the shame that employees feel toward violating Shadow IT policies. In these scenarios, employees feel that either because the action is necessary or because no one is truly injured, they do not need to feel shame in violating the policy. This mechanism seems to work differently in other neutralization techniques. It could be that when employees use the "condemn the condemner," "denial of responsibility," or "appeal to higher loyalties" techniques, reducing shame is not the goal. Rather, in these scenarios, employees still feel shame but consider violating policies for other reasons. This interesting finding points to a further need to understand exactly how neutralization techniques work cognitively. While previous research has indicated that neutralization techniques work by reducing shame [15], such a relationship only seems to hold for certain types of neutralization. Even though shame was not a mediator in the full model of Shadow IT usage, shame has a relationship with some neutralization techniques; thus, it may act as a mediator in other contexts where shame plays a more powerful deterrent role. Thus, the results provide valuable insights for further research on the interactive role of neutralization and deterrence in information security violations.

Fourth, this study indicates that the direct effects of neutralization on intentions and behavior are actually quite similar, at least in the context of Shadow IT usage. The results of this study also provide initial evidence that intentions act as a mediator between neutralization and actual violation behavior.

Finally, an additional interesting finding is that formal sanctions and denial of responsibility had significant relations with shame in the opposite direction as hypothesized. In the context of Shadow IT usage, perhaps those who did not expect to be formally sanctioned for shadow IT usage (e.g., because Shadow IT usage is currently so common in the workplace, and we measured formal sanctions as the perceptions of employees that they would be formally sanctioned for violating the policy) would be more likely to feel shame if they were actually recognized by the company as violating the policy. Similarly, those who are more prone to feel that they are not responsible for the action might actually feel more shame because it would be unexpected that they would be found in violation of policies.

\subsection{Implications for practice}

Overall, a better understanding of how to limit Shadow IT usage is of paramount importance to practice. For example, a New Yorkbased hospital recently lost $\$ 4.8$ million for HIPAA violations after the electronic protected health information of 6800 patients appeared on the Internet due to Shadow IT usage by a hospital employee [66]. Given such examples, our study offers several implications for practitioners. A better understanding of neutralization techniques by organizations could lead to better risk mitigation. Indeed, employees tend to rely on neutralization techniques when deciding to violate policies. By further acknowledging and understanding the predictors of employee intentions to be non-compliant, IT executives will have more insight into the organizational threat landscape. More specifically, our study could contribute to the development of more effective IT security training or educational programs. Such programs that encourage

Table 4

Summary of hypothesis support.

\begin{tabular}{|c|c|c|c|}
\hline Direct Effects with Intentions & Supported? & Effects on Shame as Mediator $^{\mathrm{b}}$ & Supported? \\
\hline H1 Shame $(-)$ & Partially $^{\mathrm{a}}$ & & \\
\hline H2a Formal sanctions (-) & No & H4a. Formal sanctions (+) & No \\
\hline H2b Informal sanctions $(-)$ & No & H4b. Informal sanctions (+) & Partially ${ }^{\mathrm{b}}$ \\
\hline H3a Defense of necessity $(+)$ & No & H5a. Defense of necessity (-) & Partially $^{\mathrm{b}}$ \\
\hline H3b Appeal to higher loyalties (+) & No & H5b. Appeal to higher loyalties (-) & No \\
\hline $\mathrm{H} 3 \mathrm{c}$ Condemn the condemners $(+)$ & No & H5c. Condemn the condemners $(-)$ & No \\
\hline H3d Metaphor of the ledger $(+)$ & Yes & H5d. Metaphor of the ledger $(-)$ & Partially $^{\mathrm{b}}$ \\
\hline H3e Denial of injury $(+)$ & No & H5e. Denial of injury $(-)$ & Partially $^{\mathrm{b}}$ \\
\hline H3f Denial of responsibility (+) & No & H5f. Denial of responsibility $(-)$ & No \\
\hline H6 Intentions $\rightarrow$ Actual Usage $(+)$ & Yes & & \\
\hline
\end{tabular}

a Shame was statistically significantly related to intentions in the simplified model but not in the full model.

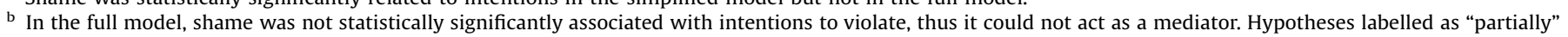
supported in this column indicate that the construct was related to shame, even though shame did not have a significant relationship with intentions. 
employees not to neutralize their behavior can reduce intentions to violate policy (Barlow et al. [19]); in this case, organizations could encourage employees not to use Shadow IT by explaining that the "metaphor of the ledger" is not an appropriate justification for violating the policy.

\subsection{Theoretical contributions}

Our research offers three new contributions to the information systems security literature. First, we identified rationalizations that are associated with the Shadow IT context, clarifying the complex interplay between rationalizations and Shadow IT as a form of a specific deviant act. Though previous research has found other neutralization techniques to be salient in other contexts (e.g., $[15,19])$, we found that the "metaphor of the ledger" technique is particularly salient for employees considering using Shadow IT in violation of organizational security policies.

Second, this study was the first to examine the effects of neutralization techniques on both intentions to violate and actual violation of a security policy. Previous research has suggested the need for information security researchers to examine both (1) the predictors of actual security behavior instead of only intentions [23] and (2) the relationship between intentions and behavior in information security contexts [24]. To our knowledge, our study is the first study about neutralization in information security to do so. We found that neutralization has similar effects on intentions and behavior. This finding also strengthens the validity of previous research that only measured intentions without measuring actual violations of security policies.

Finally, this study was the first to explicitly theorize and empirically test shame as a mediator of neutralization techniques and non-compliant behavior. Although previous research suggested such a link, none of the previous studies on neutralization in information security tested this link. We found that neutralization techniques and deterrence techniques are both related to the levels of shame that employees perceive when violating a security policy such as using Shadow IT. While shame was not a significant predictor of actual violation behavior in this context, the role that shame plays as a result of neutralization is important to consider in future research and other contexts.

\subsection{Future research and limitations}

One of the limitations of this study is that, even though the companies examined have strict policies in place regarding Shadow IT, some users were potentially not fully aware that they were committing a security violation by using Shadow IT. We do not know what happened in all organizations as far as punishment is concerned. The organizations in our study did not want to share such information fully, as it was considered to be a sensitive topic. Thus, we cannot be sure whether any given participant had seen examples of real punishment for Shadow IT usage prior to participating in the study. However, the organizations we studied do take some visible preventative action, so employees should be aware that Shadow IT usage is frowned upon in the organizations. The reasons for intentional violations may be different from the reasons for unintentional violations [23]. Future research should examine this, especially in the context of violations that are common among employees, such as Shadow IT usage.

This study also only measured perceptions of formal and informal sanctions, rather than measuring the impact of the actual formal sanctions in place in the organizations. This may explain why formal sanctions were not a strong predictor of intentions in this particular study, contrary to deterrence theory. Future research is needed to continue to understand the reasons for Shadow IT usage even when formal sanctions are in place.

Another limitation is that the concept of shame may be understood differently by different individuals or in different cultures. We aimed to be clear in the survey items related to shame, but it is a cultural construct that should be further examined in the context of IT security violations in future research.

Future research could also focus on specific types of training or organizational interventions that could be effective in reducing Shadow IT usage, especially considering that employees are prone to justify such usage. Trainings that incorporate the factors likely to lead to Shadow IT usage should be developed and tested in future research studies.

Finally, research should continue to examine the role that shame plays when employees use neutralization techniques. This study showed a relationship between three neutralization techniques and shame. In contexts where shame is a more powerful predictor of security-related behavior, it may play a key mediating role between neutralization, intentions, and behavior.

\section{Appendix A. Measurement Items}

\section{Appendix B. Model Validation}

We inspected reliability and validity coefficients of the measurement model by following the procedure as described by Gefen and Straub [67]. Regarding reliability, we examined the coefficients of composite reliability and Cronbach's $\alpha$. According to Chin and Gopal [68], composite reliability represents a more rigorous approximation of internal consistency. We present reliability results in Table B3. The composite reliabilities of the different measures range from 0.898 to 0.995 . All scales exceeded the recommended thresholds of 0.70 for Cronbach's $\alpha$ and composite reliability [69]. Our results indicate a good reliability of the measurement model.

To assess the convergent validity of the measurement model, we used two approaches. We started by analyzing the factor loadings and t-values of all indicators. T-values represent the ratio of estimates divided by standard errors where the resulting ratio tells us how many standard-error units the coefficient is away from zero. As shown in Table B1, all indicators have highly significant tvalues. All indicators exceeded factors loadings of 0.70 . Finally, following the recommendation of [70], we calculated the average variances extracted (AVEs) for each scale. The average variance extracted (AVE) for each variable construct exceeds the recommended 0.50 threshold. This indicates that the data largely supports convergent validity.

The discriminant validity test is shown in Table B2, where the square root of the reflective constructs' AVE is on the diagonal and the correlations between the constructs are in the lower left triangle. According to the Fornell-Larcker criterion [70], the AVE of each latent construct should be higher than the construct's highest squared correlation with any other latent construct, which is the case in our data.

As can be observed in Table B2, several neutralization techniques were highly correlated with each other. According to Siponen et al. [64], who also studied the effects of neutralization on a specific type of security concern, "This is to be expected, since each of the techniques represents different forms of the same overall phenomenon" (p. 339). However, we proceeded with testing the existence of multicollinearity problems by calculating variance inflation factor (VIF) scores. Results did not reveal any VIF score higher than 7.1 which is below the recommended acceptable 
Table A1

Measurement Items.

\begin{tabular}{|c|c|c|}
\hline Constructs & Items & Source \\
\hline Intention & $\begin{array}{l}\text { What is the chance that you would install or use unapproved software, hardware or any other service or product that did not receive } \\
\text { any formal IT department approval? }\end{array}$ & {$[26]$} \\
\hline Denial of responsibility & $\begin{array}{l}\text { It is OK to violate the company information security policy if you aren't sure what the policy is. } \\
\text { It is OK to violate the company information security policy if the policy is not advertised. } \\
\text { It is OK to violate the company information security policy if you don't understand it. }\end{array}$ & [15] \\
\hline Denial of injury & $\begin{array}{l}\text { It is OK to violate the company information security policy if no harm is done. } \\
\text { It is OK to violate the company information security policy if no damage is done to the company. } \\
\text { It is OK to violate the company information security policy if no one gets hurt. }\end{array}$ & [15] \\
\hline $\begin{array}{l}\text { Condemnation of the } \\
\text { condemners }\end{array}$ & $\begin{array}{l}\text { It is not as wrong to violate a company information security policy that is not reasonable. } \\
\text { It is not as wrong to violate a company information security policy that requires too much time to comply with. } \\
\text { It is not as wrong to violate a company information security policy that is too restrictive. }\end{array}$ & [15] \\
\hline Appeal to higher loyalties & $\begin{array}{l}\text { It is all right to violate a company information security policy to get a job done. } \\
\text { It is all right to violate a company information security policy if you get your work done. } \\
\text { It is all right to violate a company information security policy if you complete the task given by management. }\end{array}$ & [15] \\
\hline Defense of necessity & $\begin{array}{l}\text { It is all right to violate the company information security policy under circumstances where it seems like you have little other choice. } \\
\text { It is all right to violate the company information security policy when you are under a tight deadline. } \\
\text { It is all right to violate the company information security policy when you are in a hurry. }\end{array}$ & [15] \\
\hline Metaphor of the ledger & $\begin{array}{l}\text { I feel my general adherence to company information security policy compensates for occasionally violating an information security } \\
\text { policy. } \\
\text { I feel my good job performance compensates for occasionally violating information security policy. } \\
\text { I feel my hard work in the company compensates for occasionally violating an information security policy. }\end{array}$ & [38] \\
\hline $\begin{array}{l}\text { Formal sanctions- } \\
\text { certainty }\end{array}$ & $\begin{array}{l}\text { What is the chance you would receive sanctions if you violated the company information security policy? } \\
\text { What is the chance that you would be formally sanctioned if management learned that you had violated company information } \\
\text { security policy? } \\
\text { What is the chance that you would be formally reprimanded if management learned you had violated company information security } \\
\text { policy? }\end{array}$ & {$[26,27]$} \\
\hline $\begin{array}{l}\text { Formal sanctions- } \\
\text { severity }\end{array}$ & $\begin{array}{l}\text { How much of a problem would it be if you received severe sanctions if you violated the company information security policy? } \\
\text { How much of a problem would it create in your life if you were formally sanctioned for doing Shadow IT actions } \\
\text { How much of a problem would it create in your life if you were formally reprimanded for doing Shadow IT actions }\end{array}$ & {$[26,27]$} \\
\hline $\begin{array}{l}\text { Informal sanctions- } \\
\text { certainty }\end{array}$ & $\begin{array}{l}\text { How likely is it that you would lose the respect and good opinion of your co-workers for violating the company information security } \\
\text { policy? } \\
\text { How likely is it that you would jeopardize your promotion prospects if management learned that you had violated company } \\
\text { information security policy? } \\
\text { How likely is it that you would lose the respect and good opinion of your manager, if management learned that you had violated } \\
\text { company IT security policies? }\end{array}$ & {$[26,27]$} \\
\hline $\begin{array}{l}\text { Informal sanctions- } \\
\text { severity }\end{array}$ & $\begin{array}{l}\text { How much of a problem would it create in your life if you lost the respect and good opinion of your co- workers for violating the } \\
\text { company information security policy? } \\
\text { How much of a problem would it create in your life if you jeopardised your future job promotion prospects for doing Shadow IT } \\
\text { actions } \\
\text { How much of a problem would it create in your life if you lost the respect of your manager for violating the company information } \\
\text { security policy? }\end{array}$ & {$[26,27]$} \\
\hline $\begin{array}{l}\text { Certainty of shame for } \\
\text { oneself }\end{array}$ & $\begin{array}{l}\text { How likely is it that you would be ashamed if co- workers knew that you had violated company information security policy? } \\
\text { How likely is it that you would be ashamed if others knew that you had violated the company information security policy? } \\
\text { How likely is it that you would be ashamed if managers knew that you had violated the company information security policy? }\end{array}$ & {$[26,27]$} \\
\hline $\begin{array}{l}\text { Severity of shame for } \\
\text { oneself }\end{array}$ & $\begin{array}{l}\text { How much of a problem would it be if you felt ashamed that co-workers knew you had violated the company information security } \\
\text { policy? } \\
\text { How much of a problem would it be if you felt ashamed that others knew you had violated the company information security policy? } \\
\text { How much of a problem would it be if you felt ashamed that managers knew you had violated the company information security } \\
\text { policy? }\end{array}$ & {$[26,27]$} \\
\hline
\end{tabular}

${ }^{a}$ Dropped to improve reliability or construct validity.

VIF value of 10 [71-74]. We conclude that multicollinearity is not an issue in our data.

\section{Appendix C. Addressing Common Method Variance}

To address and mitigate possible common method variance (CMV), we used the following strategy. First, we assured full anonymity and confidentiality to respondents. Next, we randomized the order of the questions using survey software. Indeed, counterbalancing the order of constructs questions makes CMV less likely, because participants cannot then easily combine related items to cognitively "create" the correlation needed to produce a CMV-biased pattern of responses [75]. We also highlighted that there are no right or wrong answers and that respondents should be as honest as possible when answering survey questions. Additionally, we tried to examine all constructs to ensure that ambiguous, vague, and unfamiliar terms were not included. We completed all these steps to reduce problems in the comprehension stage of the response process.

In order to check for CMV, we used Harman's single-factor test [76,77]. As this test has some known limitations [78], we proceeded with another procedure to test if common method variance (CMV) would significantly impact the yielded measurement criteria. We started by estimating the model with an additional, unrelated latent common methods variance factor as proposed by Podsakoff, MacKenzie, Lee and Podsakoff [76]. To achieve that we constrained the factor loadings on the common method factor to be equal inside each group. By comparing the two models, we concluded that CMV did not significantly impact our original model because all item loadings of manifest indicators on the latent common method factor were small and non-significant. 
Table B1

Item Loadings.

\begin{tabular}{|c|c|c|c|c|c|c|c|c|c|c|c|}
\hline LV & ITEM & DOR & DOI & $\mathrm{COC}$ & AHL & DON & MOL & FS & IS & SHAME & $\begin{array}{l}\mathrm{t}- \\
\text { value }\end{array}$ \\
\hline \multirow[t]{3}{*}{ DOR } & DOR1 & 0.865 & & & & & & & & & 65.027 \\
\hline & DOR2 & 0.909 & & & & & & & & & 86.590 \\
\hline & DOR3 & 0.955 & & & & & & & & & 140.483 \\
\hline \multirow[t]{3}{*}{ DOI } & DOI1 & & 0.997 & & & & & & & & 1763.267 \\
\hline & DOI2 & & 0.986 & & & & & & & & 689.849 \\
\hline & DOI3 & & 0.995 & & & & & & & & 1426.633 \\
\hline \multirow[t]{3}{*}{$\mathrm{COC}$} & $\mathrm{COC} 1$ & & & 0.888 & & & & & & & 75.610 \\
\hline & $\mathrm{COC} 2$ & & & 0.97 & & & & & & & 194.155 \\
\hline & $\mathrm{COC} 3$ & & & 0.928 & & & & & & & 119.816 \\
\hline \multirow[t]{3}{*}{ AHL } & AHL1 & & & & 0.991 & & & & & & 951.056 \\
\hline & AHL2 & & & & 0.998 & & & & & & 1692.107 \\
\hline & AHL3 & & & & 0.978 & & & & & & 451.259 \\
\hline \multirow[t]{3}{*}{ DON } & DON1 & & & & & 0.873 & & & & & 74.021 \\
\hline & DON2 & & & & & 0.989 & & & & & 478.086 \\
\hline & DON3 & & & & & 0.983 & & & & & 416.682 \\
\hline \multirow[t]{2}{*}{ MOL } & MOL1 & & & & & & 0.936 & & & & 108.786 \\
\hline & MOL2 & & & & & & 0.941 & & & & 113.285 \\
\hline \multirow[t]{6}{*}{ FS } & FSC1 & & & & & & & 0.743 & & & 15.803 \\
\hline & FSC2 & & & & & & & 0.723 & & & 20.956 \\
\hline & FSC3 & & & & & & & 0.721 & & & 20.901 \\
\hline & FSS1 & & & & & & & 0.817 & & & 50.486 \\
\hline & FSS2 & & & & & & & 0.992 & & & 331.018 \\
\hline & FSS3 & & & & & & & 0.962 & & & 231.784 \\
\hline \multirow[t]{6}{*}{ IS } & ISC1 & & & & & & & & 0.8 & & 42.386 \\
\hline & ISC2 & & & & & & & & 0.869 & & 60.916 \\
\hline & ISC3 & & & & & & & & 0.906 & & 80.712 \\
\hline & ISS1 & & & & & & & & 0.888 & & 75.524 \\
\hline & ISS2 & & & & & & & & 0.943 & & 113.305 \\
\hline & ISS3 & & & & & & & & 0.926 & & 101.820 \\
\hline \multirow[t]{6}{*}{ SHAME } & CSO1 & & & & & & & & & 0.986 & 519.140 \\
\hline & $\mathrm{CSO} 2$ & & & & & & & & & 0.986 & 531.031 \\
\hline & $\mathrm{CSO} 3$ & & & & & & & & & 0.953 & 204.391 \\
\hline & SSO1 & & & & & & & & & 0.912 & 106.918 \\
\hline & $\mathrm{SSO} 2$ & & & & & & & & & 0.885 & 81.055 \\
\hline & $\mathrm{SSO} 3$ & & & & & & & & & 0.899 & 91.716 \\
\hline
\end{tabular}

Table B2

Discriminant validity (inter-correlations) of variable constructs.

\begin{tabular}{|c|c|c|c|c|c|c|c|c|c|}
\hline & DOR & DOI & $\mathrm{COC}$ & AHL & DON & MOL & FS & IS & SHAME \\
\hline DOR & 0.910 & & & & & & & & \\
\hline DOI & 0.881 & 0.993 & & & & & & & \\
\hline $\mathrm{COC}$ & 0.918 & 0.925 & 0.929 & & & & & & \\
\hline AHL & 0.840 & 0.896 & 0.907 & 0.989 & & & & & \\
\hline DON & 0.873 & 0.826 & 0.865 & 0.939 & 0.950 & & & & \\
\hline MOL & 0.656 & 0.799 & 0.732 & 0.842 & 0.757 & 0.939 & & & \\
\hline FS & -0.020 & -0.035 & -0.028 & 0.012 & 0.000 & -0.128 & 0.779 & & \\
\hline IS & -0.153 & -0.300 & -0.196 & -0.221 & -0.147 & -0.422 & 0.542 & 0.891 & \\
\hline SHAME & -0.188 & -0.382 & -0.273 & -0.353 & -0.266 & -0.521 & 0.364 & 0.890 & 0.938 \\
\hline
\end{tabular}

Note: Numbers on the diagonal are square roots of the AVEs.

Table B3

Assessment of the measurement model.

\begin{tabular}{llll}
\hline Constructs & AVE & $\begin{array}{l}\text { Composite } \\
\text { Reliability }\end{array}$ & Cronbach's $\alpha$ \\
\hline Appeal to Higher Loyalties (AHL) & 0.978 & 0.993 & 0.992 \\
Condemn the Condemners (COC) & 0.864 & 0.950 & 0.945 \\
Denial of Injury (DOI) & 0.985 & 0.995 & 0.995 \\
Defense of Necessity (DON) & 0.902 & 0.965 & 0.955 \\
Denial of Responsibility (DOR) & 0.829 & 0.936 & 0.935 \\
Metaphor of the Ledger (MOL) & 0.881 & 0.937 & 0.969 \\
Formal Sanctions (FS) & 0.608 & 0.898 & 0.924 \\
Informal Sanctions (IS) & 0.792 & 0.958 & 0.957 \\
Shame & 0.879 & 0.978 & 0.981 \\
\hline
\end{tabular}

Please cite this article in press as: M. Silic, et al., A new perspective on neutralization and deterrence: Predicting shadow IT usage, Inf. Manage. (2017), http://dx.doi.org/10.1016/j.im.2017.02.007 


\section{References}

[1] P. Puhakainen, M. Siponen, Improving employees' compliance through information systems security training: an action research study, MIS Q. 34 (2010) 757-778.

[2] R. Willison, M. Warkentin, Beyond deterrence: an expanded view of employee computer abuse, MIS Quarterly 37 (2013) 1-20.

[3] PwC, US cybercrime: Rising risks, reduced readiness - Key findings fromthe 2014 US State of Cybercrime Survey in 2014

[4] PwC, The Global State of Information Security, (2014).

[5] C.L. Huth, D.W. Chadwick, W.R. Claycomb, I. You, Guest editorial: a brief overview of data leakage and insider threats, Inf. Syst. Front. 15 (2013) 1-4.

[6] M. Siponen, M.A. Mahmood, S. Pahnila, Employees' adherence to information security policies: an exploratory field study, Inf. Manag. 51 (2014) 217-224.

[7] S. Behrens, W. Sedera, Why do shadow systems exist after an ERP implementation? Lessons from a case study, 8th Pacific Asia Conference on Information Systems, Shanghai, China, 2004.

[8] B. Harley, C. Wright, R. Hall, K. Dery, Management reactions to technological change the example of enterprise resource planning, J. Appl. Behav. Sci. 42 (2006) 58-75.

[9] M. Silic, A. Back, Shadow IT-a view from behind the curtain, Comput. Secur. 45 (2014) 274-283.

[10] Computerworld, IBM Tackles 'shadow It' with a New Cloud Security Tool for Enterprises, (2015).

[11] Cloud Security, Cloud Adoption, Practices and Priorities Survey Report, (2014).

[12] S. Behrens, Shadow systems: the good, the bad and the ugly, Commun. ACM 52 (2009) 124-129.

[13] J. D’Arcy, A. Hovav, D. Galletta, User awareness of security countermeasures and its impact on information systems misuse: a deterrence approach, Inf. Syst.Res. 20 (2009) 79-98.

[14] J. D'Arcy, T. Herath, A review and analysis of deterrence theory in the IS security literature: making sense of the disparate findings, Eur. J. Inf. Syst. 20 (2011) 643-658.

[15] M. Siponen, A. Vance, Neutralization New insights into the problem of employee systems security policy violations, MIS Q. 34 (2010) 487-502.

[16] G.M. Sykes, D. Matza, Techniques of neutralization: a theory of delinquency, Am. Sociol. Rev. (1957) 664-670.

[17] R. Wortley, Guilt, shame and situational crime prevention, in: R. Homel (Ed.), The Politics and Practice of Situational Crime Prevention, Criminal Justice Press, Monsey, NY, 1996, pp. 115-132.

[18] S. Haag, A. Eckhardt, Normalizing the shadows -The role of symbolic models for individuals' shadow IT usage, Proceedings of the 2014 International Conference on Information Systems (ICIS) (2014).

[19] J.B. Barlow, M. Warkentin, D. Ormond, A.R. Dennis, Don't make excuses! Discouraging neutralization to reduce IT policy violation, Comput. Secur. 39 (2013) 145-159.

[20] A. Vance, P.B. Lowry, D. Eggett, Using accountability to reduce access policy violations in information systems, J. Manage. Inf. Syst. 29 (2013) 263-290.

[21] C.L. Anderson, R. Agarwal, Practicing safe computing: a multimedia empirical examination of home computer user security behavioral intentions, MIS Q. 34 (2010) 613-643.

[22] M.A. Mahmood, M. Siponen, D. Straub, H.R. Rao, T. Raghu, Moving toward black hat research in information systems security: an editorial introduction to the special issue, MIS Q. 34 (2010) 431-433.

[23] R.E. Crossler, A.C. Johnston, P.B. Lowry, Q. Hu, M. Warkentin, R. Baskerville, Future directions for behavioral information security research, Comput. Secur. 32 (2013) 90-101.

[24] M. Warkentin, D. Straub, K. Malimage, Measuring secure behavior: A research commentary, Annual Symposium on Information Assurance \& Secure Knowledge Management, Albany, NY, 2012, pp. 1-8.

[25] B. Kim, T.C. Pratt, D. Wallace, Adverse neighborhood conditions and sanction risk perceptions: using SEM to examine direct and indirect effects, J. Quant. Criminol. 30 (2014) 505-526.

[26] R. Paternoster, S. Simpson, Sanction threats and appeals to morality: testing a rational choice model of corporate crime, Law Soc. Rev. (1996) 549-583.

[27] D.S. Nagin, R. Paternoster, Enduring individual differences and rational choice theories of crime, Law Soc. Rev. 27 (1993) 467-496.

[28] B. Bulgurcu, H. Cavusoglu, I. Benbasat, Information security policy compliance: an empirical study of rationality-based beliefs and information security awareness, MIS Quarterly 34 (2010) 523-548.

[29] A.C. Johnston, M. Warkentin, Fear appeals and information security behaviors: an empirical study, Mis Q. 34 (2010) 549-566.

[30] A. Vance, D. Eargle, K. Ouimet, D. Straub, Enhancing password security through interactive fear appeals: a web-Based field experiment, 46th Hawaii International Conference on System Sciences (HICSS), IEEE (2013) 2988-2997.

[31] L. Myyry, M. Siponen, S. Pahnila, T. Vartiainen, A. Vance, What levels of moral reasoning and values explain adherence to information security rules? An empirical study, Eur. J. Inf. Syst. 18 (2009) 126-139.

[32] Q. Hu, T. Dinev, P. Hart, D. Cooke, Managing employee compliance with information security policies: the critical role of top management and organizational culture, Decis. Sci. 43 (2012) 615-660.

[33] T. Herath, H.R. Rao, Protection motivation and deterrence: a framework for security policy compliance in organisations, Eur. J. Inf. Syst. 18 (2009) 106-125.

[34] J. Lee, Y. Lee, A holistic model of computer abuse within organizations, Inf. Manage. Comput. Secur. 10 (2002) 57-63.
[35] D.W. Straub, W.D. Nance, Discovering and disciplining computer abuse in organizations: a field study, MIS Q. 14 (1990) 45.

[36] Q. Hu, Z. Xu, T. Dinev, H. Ling, Does deterrence work in reducing information security policy abuse by employees? Commun. ACM 54 (2011) 54-60.

[37] A. Piquero, S. Tibbetts, Specifying the direct and indirect effects of low selfcontrol and situational factors in offenders' decision making: toward a more complete model of rational offending, Justice Q. 13 (1996) 481-510.

[38] S.L. Eliason, R.A. Dodder, Techniques of neutralization used by deer poachers in the western United States: a research note, Deviant Behav. 20 (1999) 233-252.

[39] K.H. Guo, Y. Yuan, N.P. Archer, C.E. Connelly, Understanding nonmalicious security violations in the workplace: a composite behavior model, J. Manage. Inf. Syst. 28 (2011) 203-236.

[40] M. Warkentin, R. Willison, Behavioral and policy issues in information systems security: the insider threat, Eur. J. Inf. Syst. 18 (2009) 101-105.

[41] S.L. McGregor, Conceptualizing immoral and unethical consumption using neutralization theory, Family Consum. Sci. Res. J. 36 (2008) 261-276.

[42] C.B. Klockars, The Professional Fence, Free Press, New York, 1974.

[43] W.W. Minor, Techniques of neutralization: a reconceptualization and empirical examination, J. Res. Crime Delinquency 18 (1981) 295-318.

[44] L. Cao, Major Criminological Theories: Concepts and Measurement, Wadsworth Publishing, Belmont, CA, 2004.

[45] J.R. Ingram, S. Hinduja, Neutralizing music piracy: an empirical examination, Deviant Behav. 29 (2008) 334-366.

[46] V.K. Lim, The IT way of loafing on the job: cyberloafing, neutralizing and organizational justice, J. Organizational Behav. 23 (2002) 675-694.

[47] S.J. Harrington, The effect of codes of ethics and personal denial of responsibility on computer abuse judgments and intentions, MIS Q. 20 (1996) 257-278.

[48] A. Györy, A. Cleven, F. Uebernickel, W. Brenner, Exploring the shadows: IT governance approaches to user-Driven innovation, European Conference on Information Systems (2012) 222.

[49] M. Silic, Dual-use open source security software in organizations -Dilemma: help or hinder? Comput. Secur. 39 (2013) 386-395.

[50] D.M. Strong, O. Volkoff, A roadmap for enterprise system implementation, Computer 37 (2004) 22-29.

[51] D. Oliver, C.T. Romm, ERP Systems in Universities: Rationale Advanced for Their Adoption, Idea Group Publishing, Hershey, PA, 2002.

[52] M. Warkentin, Information systems security and privacy, Adv. Telematics 3 (1995) 57-77.

[53] T.J. Winkler, C.V. Brown, Horizontal allocation of decision rights for on-Premise applications and software-as-a-Service, J. Manage. Inf. Syst. 30 (2013) 13-48.

[54] S. Alter, Theory of workarounds, Commun. Assoc. Inf. Syst. 34 (2014) 1041 1066.

[55] J. Braithwaite, Crime, Shame and Reintegration, Cambridge University Press, 1989.

[56] I. Ajzen, M. Fishbein, Understanding Attitudes and Predicting Social Behavior, Prentice-Hall, Englewood Cliffs, NJ, 1980.

[57] I. Ajzen, The theory of planned behavior, Organ. Behav. Hum. Decis. Process. 50 (1991) 179-211.

[58] P. Ifinedo, Understanding information systems security policy compliance: an integration of the theory of planned behavior and the protection motivation theory, Comput. Secur. 31 (2012) 83-95.

[59] J. Schepers, M. Wetzels, A meta-analysis of the technology acceptance model: investigating subjective norm and moderation effects, Info. Manage. 44 (2007) 90-103.

[60] J. Wu, A. Lederer, A meta-analysis of the role of environment-based voluntariness in information technology acceptance, MIS Q. 33 (2009) 419432.

[61] M. Chan, I.M.Y. Woon, A. Kankanhalli, Perceptions of information security at the workplace: linking information security climate to compliant behavior, J. Info. Privacy Secur. 1 (2005) 18-41.

[62] M. Aguirre-Urreta, M. Rönkkö, Sample size determination and statistical power analysis in PLS using R: an annotated tutorial, Commun. Assoc. Inf. Syst. 36 (2015) 3.

[63] A.C. Johnston, M. Warkentin, M. Siponen, An enhanced fear appeal rhetorical framework: leveraging threats to the human asset through sanctioning rhetoric, MIS 0. 39 (2015) 113-134.

[64] M. Siponen, A. Vance, R. Willison, New insights into the problem of software piracy: the effects of neutralization, shame, and moral beliefs, Inf. Manage. 49 (2012) 334-341.

[65] M. Siponen, A. Vance, Guidelines for improving the contextual relevance of field surveys: the case of information security policy violations, Eur. J. Inf. Syst. 23 (2014) 289-305.

[66] E. McCann, Groups Hit with Record \$4.8 M HIPAA Fine, (2014).

[67] D. Gefen, D. Straub, A practical guide to factorial validity using PLS-Graph: tutorial and annotated example, Commun. Assoc. Inf. Syst. 16 (2005) 91-109.

[68] W.W. Chin, A. Gopal, Adoption intention in GSS: relative importance of beliefs, ACM SigMIS Database 26 (1995) 42-64.

[69] D. Gefen, D. Straub, M.-C. Boudreau, Structural equation modeling and regression: guidelines for research practice, Commun. Assoc. Inf. Syst. 4 (2000) 7.

[70] C. Fornell, D.F. Larcker, Evaluating structural equation models with unobservable variables and measurement error, J. Marketing Res. 18 (1981) 39

[71] J.F. Hair, Multivariate Data Analysis, Prentice Hall, Upper Saddle River, 2009.

[72] P. Kennedy, A Guide to Econometrics, MIT press, 2003. 
[73] D.W. Marquaridt, Generalized inverses, ridge regression, biased linear estimation, and nonlinear estimation, Technometrics 12 (1970) 591-612.

[74] M.H. Kutner, C. Nachtsheim, J. Neter, Applied Linear Regression Models, McGraw-Hill, Irwin, 2004

[75] J.Y. Murray, M. Kotabe, J.N. Zhou, Strategic alliance-based sourcing and market performance: evidence from foreign firms operating in China, J. Int. Bus. Stud 36 (2005) 187-208.

[76] P.M. Podsakoff, S.B. MacKenzie, J.-Y. Lee, N.P. Podsakoff, Common method biases in behavioral research: a critical review of the literature and recommended remedies, J. Appl. Psychol. 88 (2003) 879.

[77] P.M. Podsakoff, D.W. Organ, Self-reports in organizational research: problems and prospects, J. Manage. 12 (1986) 531-544.

[78] E.R. Kemery, W.P. Dunlap, Partialling factor scores does not control method variance: a reply to Podsakoff and Todor, J. Manage. 12 (1986) 525-530.

Mario Silic is a post-doctoral researcher at the Institute of Information Management, University of St. Gallen, Switzerland. He holds a Ph.D. from University of St Gallen, Switzerland. His research motivation focuses on the fields of information security, open source software, human-computer interaction and mobile. He has published research in Computers $\mathcal{E}$ 'Security, Information Management
E Computer Security, International Journal of Information Technology E Decision Making, and Records Management Journal.

Jordan B. Barlow is an assistant professor in the Information Systems \& Decision Sciences department at California State University, Fullerton. He received his Ph.D. in information systems from Indiana University. His research interests include virtual collaboration and information security. He has published research in MIS Quarterly, Journal of Management Information Systems, Journal of the AIS, Computers $\mathcal{E}$ Security, Group Decision and Negotiation, and Communications of the AIS.

Andrea Back is full professor of management and information systems at the University of St.Gallen, Switzerland. She is director of the research groups Mobile Business and Business 2.0 at the Institute of Information Systems. Her research interests include strategy in digital transformation, mobile and wearable computing in business processes, and enterprise social networks. She teaches in the Ph.D. and Master programs Business Innovation. Book and journal publications can be found at alexandria.unisg.ch. 